Georgia State University

ScholarWorks @ Georgia State University

\title{
A Randomized Controlled Trial of the Concrete Biosand Filter and its Impact on Diarrheal Disease in Bonao, Dominican Republic.
}

Christine E. Stauber

Georgia State University

Gloria M. Ortiz

Dana P. Loomis

University of North Carolina at Chapel Hill

Mark Sobsey

University of North Carolina at Chapel Hill

Follow this and additional works at: https://scholarworks.gsu.edu/iph_facpub

Part of the Public Health Commons

\section{Recommended Citation}

Stauber, C.E., G.M. Ortiz, D.P. Loomis, and M.D. Sobsey. 2009. A Randomized Controlled Trial of the Concrete Biosand Filter and its Impact on Diarrheal Disease in Bonao, Dominican Republic. American Journal of Tropical Medicine and Hygiene, 80(2):286-293.

This Article is brought to you for free and open access by the School of Public Health at ScholarWorks @ Georgia State University. It has been accepted for inclusion in Public Health Faculty Publications by an authorized administrator of ScholarWorks @ Georgia State University. For more information, please contact scholarworks@gsu.edu. 


\title{
A Randomized Controlled Trial of the Concrete Biosand Filter and Its Impact on Diarrheal Disease in Bonao, Dominican Republic
}

\author{
Christine E. Stauber,* Gloria M. Ortiz, Dana P. Loomis, and Mark D. Sobsey \\ Department of Environmental Science and Engineering, School of Public Health, The University of North Carolina, \\ Chapel Hill, North Carolina; School of Public Health, The University of Nevada, Reno, Nevada
}

\begin{abstract}
A number of household water treatment and safe storage technologies, such as chlorine disinfection, solar disinfection, and ceramic filtration, have been documented for their ability to reduce diarrheal disease and improve microbial water quality. The biosand filter (BSF) is a promising household water treatment technology in use by $>500,000$ people globally. The purpose of this research was to document the ability of BSFs to improve water quality and to reduce diarrheal disease in user compared with non-user households in a randomized controlled trial in Bonao, Dominican Republic, during 2005-2006. During the 6-month intervention period, 75 BSF households had significantly improved drinking water quality on average compared with 79 control households $(P<0.001)$. Based on random intercepts logistic regression, BSF households had 0.53 times the odds of diarrheal disease as control households, indicating a significant protective effect of the BSF against waterborne diarrheal disease.
\end{abstract}

\section{INTRODUCTION}

More than 1 million people die annually as a result of diarrheal diseases. Although mortality from diarrheal disease is decreasing globally, morbidity is not. The average child in developing countries experiences three or more cases of diarrheal disease each year, accounting for up to 4 billion cases annually. ${ }^{1}$ Diarrheal diseases make up $4 \%$ of the global burden of disease. A recent review suggested that the environment and environmental risk factors play an important role in the global burden of diseases. This review estimated that $94 \%$ of diarrheal diseases are attributed to a "reasonably modifiable environment" and suggested that interventions can be made in water, sanitation, and hygiene in an attempt to decrease the burden of diarrheal disease. ${ }^{2}$

Studies on household drinking water quality interventions have documented reductions in diarrheal disease by $31 \%$ and significant improvements in drinking water quality. ${ }^{3}$ A promising household water treatment technology is the biosand filter (BSF). The BSF is an intermittently operated slow sand filter with a concrete, plastic, or metal housing. According to current estimates, the BSF has been installed in $>80,000$ homes around the world. ${ }^{4}$ Laboratory research has shown that the BSF reduces fecal microbe contamination by $~ 90 \%$ for viruses, $90-99 \%$ for bacteria, and $>99.9 \%$ for protozoan parasites. ${ }^{5-7}$ The BSF, however, lacks rigorous scientific evidence of its ability to reduce diarrheal disease in users. The purpose of this study was to assess the ability of the BSF to improve water quality and reduce diarrheal disease in the field.

According to recent estimates from the Joint Monitoring Program of the World Health Organization (WHO) and United Nations' Children's Fund (UNICEF), $98 \%$ of the urban and $60 \%$ of the rural population have access to improved water in the Dominican Republic (DR). ${ }^{8}$ Although many in the population have access to a piped water source within 15 minutes of the home, these sources provide only intermittent flow and are recognized to be of poor quality. ${ }^{9}$ In addition, diarrheal disease continues to be a burden to the population; a recent national 2 -week survey reported that $14 \%$ of all children $<5$ years

* Address correspondence to Christine E. Stauber, Georgia State University, Institute of Public Health, P.O. Box 3995, Atlanta, GA 30302-3995. E-mail: cstauber@gsu.edu of age suffered from diarrhea. ${ }^{10}$ The same survey reported increased diarrheal disease burden above the national average $(14 \%)$ in four provinces in the country: Bahoruco, $24 \%$; Barahona, 24\%; Independencia, 29\%; Monseñor Nouel, 22\%. This study focused on the province of Monseñor Nouel.

Determining the microbiologic effectiveness and health impact of the BSF is a critical need in the DR because the concrete housing model is already being used by thousands of people in the country. BSFs were first made in the DR in 2000, and since then, almost 10,000 filters have been installed. As a result of the higher diarrheal disease prevalence and limited implementation of the BSF in the area, Bonao, the capital of the province, was selected as the study site. The purpose of this study was to perform a randomized controlled trial (RCT) of the concrete housing BSF. The study was designed to evaluate the impact of newly installed BSF use on diarrheal disease and water quality.

\section{MATERIALS AND METHODS}

Research setting and population. The study was performed in two communities within Bonao: one semi-rural, called Jayaco; the other urban, called Brisas del Yuna. Field data collection began on June 19, 2005 and was completed on July 27, 2006. A cross-sectional study was performed from June to August 2005 in the two communities. Before beginning the survey, informed consent was obtained from all households for all participants in the household. Requirements for inclusion in the study were as follows: no BSF in the household, at least one child $<5$ years of age, and willingness to participate. Because diarrheal disease burden falls most heavily on children $<5$ years old, all households with children $<5$ years of age were targeted for the cross-sectional recruitment interview. The areas of the communities that already had BSFs were excluded. The purpose of the cross-sectional study was to collect data on diarrheal disease prevalence in households and potential risk factors for diarrheal disease including socio-economic status and access to sanitation. The households were asked to participate in the longitudinal portion of the RCT of the BSF.

The intervention. Households were visited weekly for 4 months before randomization into BSF and control groups. The purpose of household visits before BSF intervention was to determine and compare diarrheal disease and water quality 
in the BSF and control groups before installation of the BSF. During this time period, interview staff collected information on drinking water sources, household water management practices, and diarrheal disease. In addition, staff collected drinking water samples every 2 weeks.

Households were unaware of whether they would be assigned to the BSF intervention or control (no BSF) group until 1 week before BSF installation. Households were assigned a unique number; random numbers were generated to identify the $50 \%$ of the participating households selected to receive the BSF. Eighty-one households were selected to receive the BSF, and 86 households were selected into the control group, which did not receive any intervention during the study. Before installation of the BSF, three households selected to receive the BSF moved out of the neighborhood, and no replacement households were selected. Households were allowed to leave at any point but were not allowed to keep the filter if they left before the end of the study.

During the first week of February 2006, 81 concrete BSFs were installed in homes by a local filter technician from a national implementing organization. The technician explained use and operation of the BSF to a household participant and provided a brochure for reference. During the installation, the technician instructed households to add water to the BSF for 5 successive days before using the filtered water. The technician provided no additional educational messages on sanitation or hygiene. All households that received the BSF, however, also received a 5-gal narrow mouth bottle (no spigot) and base that allowed water to filter directly into the container for safe storage of the BSF-treated water. BSF and control households were followed weekly for 6 months after installation of the BSF. The Institutional Review Board of the University of North Carolina and the Provincial Health Sector of Monseñor Nouel, Dominican Republic, approved the study.

Diarrheal disease surveillance. A system for diarrheal disease surveillance was established as part of weekly household interviews. Local members of the community were hired and trained to deliver the cross-sectional and weekly interviews. Native Spanish-speakers translated the English questionnaires, and they were back-translated to ensure accurate translation and interpretation of the questions. In addition, interviewers tested the questionnaires in the surrounding community before beginning the survey. All interviews were conducted at the participant's house.

During the cross-sectional interview, household primary respondents were identified (typically as the primary child caregiver). At approximately 7-day intervals, the household's primary respondent was asked to verbally report cases of diarrheal disease for all participants in the household. If the primary respondents reported a case of diarrhea in any household member, they were asked the following: the date the case began, the frequency of the evacuations, the duration and a description of stool consistency, and the presence of blood in stools. Interviewers recorded all cases that met the WHO definition of diarrheal disease: three or more loose stools or any stool with blood in it in a 24-hour period. If the case was on-going at the time of the interview, the interviewer determined the date the case was resolved on the following household visit.

Longitudinal diarrheal disease surveillance began on September 19, 2005, and was completed on July 27, 2006. Diarrheal disease surveillance was not performed during the weeks beginning on December 26, 2005, January 2, 2006, and April 10, 2006 and was halted for the week beginning October 24,2005 . Sixteen full weeks of observation were conducted before BSF installation and the period after BSF installation consisted of 24 full weeks.

Drinking water quality testing. In addition to weekly household surveys, interviewers asked households to provide samples of drinking water every 2-3 weeks. After initiating the BSF intervention, households that received BSFs provided the following household water samples when available: stored source water before BSF treatment, drinking water directly from the BSF outlet, stored BSF-treated water, and stored BSFtreated water that received any additional treatment. Before BSF installation, household drinking water was sampled seven times. After BSF installation, it was sampled 11 times.

Participants poured water samples directly out of household drinking water storage containers or interviewers collected it directly from the BSF into 500-mL sterile Whirlpak bags. Samples, stored on ice, were processed within 8 hours at Dr. Mirna Peña's Clinical Laboratory, Bonao, DR. They were tested for total coliforms and E. coli using the IDEXX ColilertQuantitray system (IDEXX, Laboratories, Westbrook, $\mathrm{ME}$ ) according to the manufacturer's instructions.

In summary, $100-\mathrm{mL}$ sample volumes were combined with one packet of Colilert reagent medium in a sterile $120-\mathrm{mL}$ capacity reagent bottled containing sodium thiosulfate to neutralize chlorine. Samples were mixed briefly, poured into Quantitrays, sealed, and incubated $20-24$ hours at $35 \pm 1^{\circ} \mathrm{C}$. Quantitray wells that turned yellow were scored positive for total coliforms and those that fluoresced blue under a long wavelength UV light were scored positive for $E$. coli. The numbers of positive Quantitray wells were used to obtain most probable number (MPN) values from an MPN table provided by IDEXX.

Average monthly rainfall. Information on rainfall was provided by a mining company located in the Jayaco community. The company collected rainfall data in mines surrounding the participating communities. Monthly average rainfall $(\mathrm{mm} / \mathrm{mo})$ was provided for the entire study period (2005-2006).

Data analysis. An estimation of household wealth was made using principal components analysis (PCA) of household assets. This is a technique that has recently been applied to data from the national demographic and health surveys to determine approximate categories of wealth when no household income data were collected. ${ }^{11}$ For this study, PCA was used to evaluate and generate a household wealth score from information collected during the cross-sectional survey for the following assets: car, motorcycle, refrigerator, television, fan, washer, cellular phone, floor construction materials, access to latrines, use of gas for cooking, and primary and secondary education. Based on the results of the PCA (using principal component 1), households were classified into quintiles of wealth, and a dichotomous wealth variable was generated based on the lowest $40 \%$ bracket and the remaining households that constituted the upper $60 \%$.

Households that were not available to answer the initial crosssectional questionnaire during the 3-month period of household recruitment were classified as missing for these data (Table 1). Additional households lacked wealth information because of the way the data were analyzed using PCA. If one of the included assets was missing, the household score was not computed, and therefore, the household was classified as missing. 
TABLE 1

Age (as of September 2005), household size, and sex of participants in randomized controlled trial of concrete biosand filter in Bonao, Dominican Republic, in 2005-2006

\begin{tabular}{lccc}
\hline & $\begin{array}{c}\text { Control } \\
(N=460)\end{array}$ & $\begin{array}{c}\text { Intervention } \\
(N=447)\end{array}$ & $\begin{array}{c}P \text { values } \\
\left(\chi^{2} \text { test }\right)\end{array}$ \\
\hline Age & $N(\%)$ & $N(\%)$ & \\
Participants $\geq 5$ years old & $332(72 \%)$ & $332(74 \%)$ & \\
Participants $\geq 2$ and $<5$ & $76(17 \%)$ & $77(17 \%)$ & 0.94 \\
Participants $<2$ years old & $52(11 \%)$ & $38(9 \%)$ & 0.20 \\
Household size & $N$ & $N$ & \\
Range per household & $2-12$ & $3-15$ & \\
$\quad($ participants & & & \\
Average per household & 5.3 & 5.5 & 0.22 \\
Sex & $N$ & $N$ & \\
Male $(<5)$ & $69(54 \%)$ & $52(45 \%)$ & \\
Female $(<5)$ & $59(46 \%)$ & $63(55 \%)$ & \\
Male $(\geq 5)$ & $155(47 \%)$ & $160(48 \%)$ & 0.76 \\
Female $(\geq 5)$ & $177(53 \%)$ & $172(52 \%)$ & \\
\hline
\end{tabular}

The effect of the BSF on diarrheal disease rates was determined by comparing diarrhea incidence of BSF users (intervention households) to that of BSF non-users (control households) within respective age groups. If the participant reported diarrhea symptoms for $>1$ consecutive week, a new case of diarrhea (based on the WHO definition) was assigned only when the symptoms had been preceded by 3 or more successive days free of diarrheal disease. Diarrheal disease incidence rates were calculated by determining the number of cases divided by the number of person-weeks for each group. Diarrheal disease incidence rates were compared between the intervention and control groups for the study periods before and after the BSF intervention for three age groups: children $<2$ years of age, children $2-4$ years of age, and those $\geq 5$ years of age.

The effect of rainfall on diarrheal disease was examined using stratified analysis and a Mantel-Haenzel $(\mathrm{MH})$ test for homogeneity of effect. Rainfall (average $\mathrm{mm} / \mathrm{mo}$ ) was compared with diarrheal disease outcome each month. Rainfall rates were also compared with diarrheal disease outcome incorporating a 1-month lag. Based on the $\mathrm{MH}$ test for homogeneity of effect, average rainfall from the previous month correlated better with diarrheal disease $(\mathrm{MH}, P$ value decreased from 0.06 to $<0.05$ for rainfall groupings). As a result of the increase in heterogeneity of effect for a 1-month lag in rainfall, the effect of the BSF in the wet and dry seasons was calculated by classifying February, March, April, and July as dry season months and May and June as wet season months. Wet season was defined as the period of time when rainfall exceeded $400 \mathrm{~mm} / \mathrm{mo}$; dry season was $<400 \mathrm{~mm} / \mathrm{mo}$.

Household drinking water quality was compared for BSF and control households both before and after filter installation using the two-sample $t$ test. Because household drinking water quality was not sampled at each household visit, drinking water quality values for each month of observation were averaged and that was used as the measure of drinking water quality later evaluated in modeling. In an attempt to better characterize exposure to E. coli through drinking water, drinking water quality was calculated by averaging the quality of all water designated for consumption in both BSF and control households. This included untreated and treated drinking water in both BSF and control households.

Random intercepts logistic regression. Based on the relatively short observation time (1-week intervals) and the low risk of diarrheal disease $(<10 \%)$, the odds ratio from the logistic regression model can closely approximate the incidence rate ratio (IRR). ${ }^{12}$ To model the data, therefore, we used multivariable logistic regression. Diarrheal disease at time of visit comprised the outcome variable, and participant membership in the BSF versus control group, as classified according to intention to treat, comprised the main exposure variable. The following covariates were assessed as simple variables using a backward stepwise elimination procedure: sex, access to latrines, education, and wealth from cross-sectional data and age, water quality, and season from the longitudinal measurements. Selection criteria to keep covariates in the model were based on an a priori change in the coefficient of the exposure (BSF or control household) by $10 \%$ or more. ${ }^{13}$ After initial analysis as a confounder, season was included as an interaction variable in the final model.

Adjustment for clustering at the participant level and household level was performed by using a random intercepts logistic regression model. Mixed models are increasingly being used to account for three level hierarchical structure. ${ }^{14}$ The data from this study were modeled with a three-level hierarchical model. This model worked well for the study because individual participants were observed repeatedly, each belonging to a household that was randomized into BSF or control household. The random intercepts logistic regression model can accommodate correlation that occurs as a result of following a subject longitudinally and following multiple subjects within a household. All analyses were performed in Intercooled Stata 8.0 (Stata; StataCorp, College Station, TX).

The final model is described below:

$$
\log E\left(Y_{i j}\right)=\beta_{0 j}+\beta_{1 j}+\beta_{2 j}+\beta_{3 j}+\beta_{1 j}^{*} \beta_{3 j}+r_{i j}
$$

where $Y_{\mathrm{ij}}=$ diarrheal disease in the $i$ th person in the $j$ th household, $\beta_{0 \mathrm{j}}=$ household level factors, $\beta_{1 \mathrm{j}}=$ BSF exposure, $\beta_{2 \mathrm{j}}$ = categorical age, $\beta_{3 \mathrm{j}}=$ season, $\beta_{1 \mathrm{j}} \times \beta_{3 \mathrm{j}}=$ interaction between season and BSF, and $r_{\mathrm{ij}}=$ within-household residual variation, where $\beta_{0 j} \gamma_{00}$ (average of household intercepts) $+\gamma_{01}$ (diarrheal disease status for the individual) $+\mu_{0 j}$ (between household variation).

\section{RESULTS}

Study enrollment and completion. At the start of the longitudinal study (September 2005), 187 of 210 households that participated in the cross-sectional interview were enrolled. The major reasons for exclusion from the longitudinal study were as follows: household had moved, no longer had children $<5$ years of age living in the household, or did not want to participate. A diagram of enrollment and participation in the longitudinal study is shown in Figure 1. From September 2005 to February 2006, 20 households left the study. The primary reason for leaving was either the household moved or the child $<5$ years of age moved out of the household. After randomization, 75 (93\%) and $79(92 \%)$ of BSF and control households, respectively, completed the study. Reasons for leaving the study are shown in Figure 1.

Baseline characteristics and group comparability. At the time of BSF installation, there were 907 participants, including 243 children $<5$ years of age (Table 1 ). During randomization, 447 were members of the BSF intervention group, and 460 were in the control group. Data on household demographics 


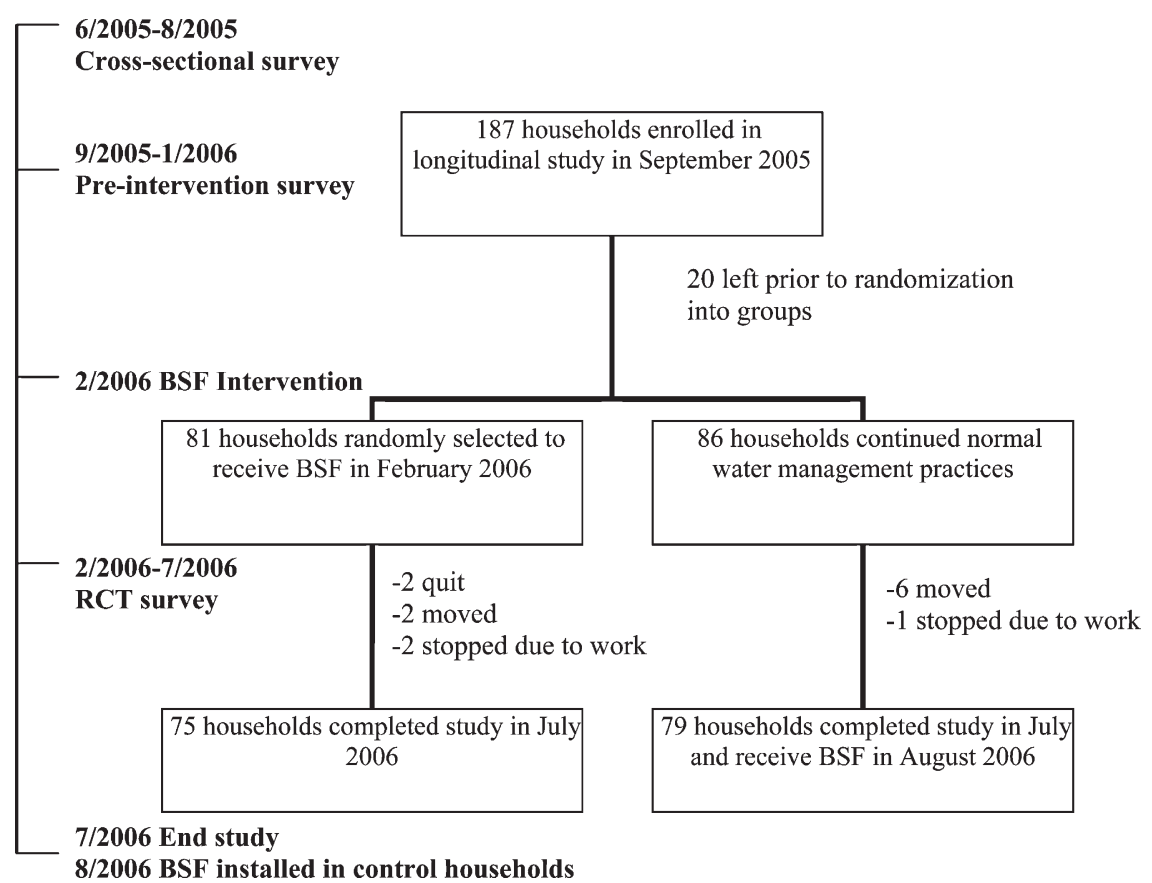

FIGURE 1. Diagram and timeline of household enrollment and participation in randomized controlled trial of the concrete biosand filter in Bonao, Dominican Republic, 2005-2006.

and characteristics collected during the cross-sectional survey are summarized in Table 2.

On randomization, there were few differences between the groups, both reporting non-significant differences in access to sanitation and water as shown in Tables 1 and 2 . During the cross-sectional interview, $\sim 20 \%$ of all households reported at least one household member having a case of diarrhea in the 7 days before the cross-sectional survey; $80 \%$ of the cases occurred in children $<5$ years of age. BSF households reported a higher prevalence of diarrheal disease during the crosssectional questionnaire, a difference that was not statistically significant $(P \geq 0.05)$. Household wealth distribution, based on PCA of assets, was significantly different $\left(P<0.05\right.$ for $\chi^{2}$ test $)$ between the two groups (Table 2). More control households were in the lowest $40 \%$ wealth bracket than intervention

TABLE 2

Selected characteristics regarding water, sanitation, hygiene, diarrheal disease, and wealth for households in randomized controlled trial of concrete biosand in Bonao, Dominican Republic, September 2005

\begin{tabular}{lccc}
\hline & $\begin{array}{c}\text { Control } \\
(N=86) \\
{[N(\%)}\end{array}$ & $\begin{array}{c}\text { Intervention } \\
(N=81) \\
{[N(\%)]}\end{array}$ & $\begin{array}{c}P \text { values } \\
\left(\chi^{2} \text { test }\right)\end{array}$ \\
\hline Water collection frequency & & & \\
1-2 times (per week) & $18(21)$ & $18(22)$ & 0.98 \\
3-5 times (per week) & $15(17)$ & $20(25)$ & 0.54 \\
7 or more times (per week) & $52(61)$ & $41(51)$ & 0.17 \\
$\quad 1(1)$ & $2(2)$ & \\
Missing & $36(42)$ & $29(36)$ & 0.52 \\
Treat drinking water & $21(24)$ & $22(27)$ & 0.86 \\
Buy bottled/vended water & $64(75)$ & $52(65)$ & 0.21 \\
Soap present & $15(17)$ & $22(27)$ & 0.19 \\
Diarrhea in last 7 days & $70(81)$ & $60(74)$ & 0.34 \\
Latrine/toilet at house & & & \\
Dichotomous wealth* & $42(49)$ & $22(27)$ & 0.006 \\
$\quad$ Lower 40\% & $41(48)$ & $56(69)$ & \\
$\quad$ Upper 60\% & $3(3)$ & $4(5)$ & \\
$\quad$ Missing & * Significant difference between the two groups detected as $P<0.05\left(\chi^{2}\right.$ test).
\end{tabular}

households. Based on these differences, this variable was evaluated during multivariate analysis.

BSF intervention and diarrheal disease. Before BSF intervention, the BSF and control households had similar incidence rates of diarrheal disease when compared overall. As shown in Table 3, the unadjusted diarrheal disease IRR of BSF households to control households before BSF intervention was 1.03 , with a $95 \%$ confidence interval $(\mathrm{CI})$ of $0.83,1.26$. After BSF intervention, however, BSF households reported 0.47 times the diarrheal disease of control households, with an IRR of 0.47 (95\% CI, 0.37, 0.59). Unadjusted diarrheal disease rates were also examined by age group before and after the BSF intervention (Table 3). The age-stratified IRRs suggest that, before intervention, BSF households experienced higher rates of diarrheal disease for those $>2$ years of age compared with controls and lower rates for those $<2$ years of age compared with controls. After BSF intervention, BSF households experienced reduced rates of diarrheal disease in all three age groups. As a result of the differences in agestratified IRRs, a categorical age variable was included in the multivariate analysis.

The average monthly diarrheal disease incidence rates for BSF and control groups are shown in Figure 2. The diarrheal data are plotted against monthly average rainfall data for the entire study. As shown in Figure 2, households showed decreased diarrheal incidence rates with high rainfall periods. This occurred in both BSF and control groups before BSF intervention and only in the control group after BSF intervention.

Use of rainwater during the intervention period fluctuated with monthly rainfall amounts. In control households, it ranged from 2.3\% in March 2006 to 13.5\% in April 2006. In BSF households, it ranged from as low as $4.9 \%$ in March to $14.3 \%$ in May. Large monthly rainfall amounts resulted in decreased rates of diarrheal disease in the control households. 
TABLE 3

Unadjusted IRRs for diarrheal disease in biosand filter and control households before and after biosand filter intervention during randomized controlled trial in Bonao, Dominican Republic, from September 2005 to July 2006

\begin{tabular}{lcccc}
\hline $\begin{array}{l}\text { Data collection } \\
\text { period }\end{array}$ & $\begin{array}{c}\text { IRR* }(95 \% \mathrm{CI}) \dagger \\
\text { for all ages }\end{array}$ & $\begin{array}{c}\text { IRR }(95 \% \mathrm{CI}) \\
\text { for }<2 \text { year olds }\end{array}$ & $\begin{array}{c}\text { IRR }(95 \% \mathrm{CI}) \\
\text { for 2-4 year olds }\end{array}$ & $\begin{array}{c}\text { IRR }(95 \% \mathrm{CI}) \\
\text { for } \geq 5 \text { year olds }\end{array}$ \\
\hline Before BSF & $1.03(0.83,1.26)$ & $0.71(0.50,0.99)$ & $1.29(0.95,1.76)$ & $1.74(1.03,2.95)$ \\
After BSF & $0.47(0.37,0.59)$ & $0.74(0.51,1.06)$ & $0.36(0.25,0.52)$ & $0.70(0.43,1.15)$ \\
\hline
\end{tabular}

* IRR with control as referent group.

$\dagger 95 \% \mathrm{CI}=95 \%$ confidence interval for the IRR.

As a result, the rainy season had a significant effect on diarrheal disease reduction by the BSF (MH test for homogeneity, $P<0.05)$.

The reduction in diarrheal disease for the BSF households versus the control households was also estimated using multivariate logistic regression models with and without an interaction term for season. Potential covariates were assessed for confounding during model formulation, and only a categorical age variable was included in the model based on the a priori $10 \%$ change in effect criterion. A random intercepts logistic regression model was chosen to adjust for clustering (see equation 1).

The results from the random intercepts logistic regression model are shown in Table 4. The odds ratio (OR) and 95\% CI of the diarrheal disease of BSF households compared with the control households was $0.53(0.36,0.79)$. Based on the results from the $\mathrm{MH}$ test for homogeneity of effect, an interaction term for season was included in the final model. The OR and 95\% CI for BSF households versus control households was $0.40(0.25,0.62)$ and $0.86(0.50,1.48)$ for dry and wet seasons, respectively (Table 4).

Water quality analysis. Household drinking water quality was compared over the entire study period for BSF and control households (including only households that completed the study). Six-month mean water quality concentrations of E. coli per $100 \mathrm{~mL}$ were computed as geometric means. As shown in Table 5, before BSF intervention, BSF and control households had similar mean MPN concentrations of E. coli per $100 \mathrm{~mL}$ in household drinking waters: 22 and 21 , respectively ( $P=0.74$, two-sample $t$ test). After intervention, BSF households had improved water quality compared with control households, based on E. coli concentrations,

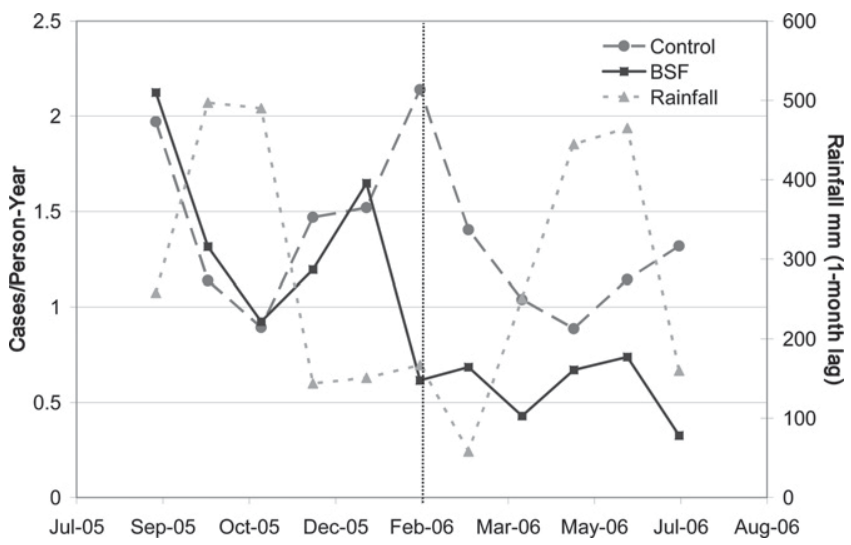

FIgURE 2. Monthly incidence rates of diarrheal disease in biosand filter and control households for randomized controlled trial in Bonao, Dominican Republic, and monthly rainfall, 2005-2006 (vertical line $=$ BSF intervention) . with 11 and 19 E. coli MPN/100 mL, respectively $(P<0.001)$. Furthermore, average water quality concentrations before and after the BSF intervention were calculated for each household and averaged for each group. BSF households showed a significant $48 \%$ reduction in $E$. coli concentration $(P<0.05)$ compared with a $9.8 \%$ non-significant reduction in control households (Table 5).

Household drinking water E. coli concentrations were also categorized into five decimal levels, <1, 1-10, 11-100, 1011,000 , and $>1,000 \mathrm{MPN} / 100 \mathrm{~mL}$, for all samples that were reported to be drinking water for children (Table 6). More than $60 \%$ of drinking water from BSF households had $\geq 10$ E. coli MPN/100 mL compared with only $45 \%$ for control households. Almost $20 \%$ of drinking water samples from control households were found to have $>100$ E. coli MPN/100 mL compared with only $12 \%$ in BSF households. The difference in proportions of relatively clean $(<10 \mathrm{E}$. coli $/ 100 \mathrm{~mL})$ and highly contaminated $(>1,000 \mathrm{E}$. coli/100 mL) water, as well as the significantly different concentrations of E. coli, suggest substantial improvements in drinking water quality in BSF households compared with control households over the intervention period.

\section{DISCUSSION}

Effect of BSF on diarrheal disease. This is the first known RCT to determine the ability of the concrete housing BSF to improve water quality and reduce diarrheal disease. The main findings of this study are that the presence of the BSF in households in Bonao, DR, was associated with significantly lower E. coli concentrations in household drinking water and decreased diarrheal disease in BSF households compared with control households during the 6-month intervention period.

BSF households reported 0.53 times as much diarrheal disease compared with control households when adjusted for participant's age and clustering. This finding of considerably less diarrheal disease in households with the BSF as a point-of-use (POU) water treatment compared with households without such treatment is consistent with studies of other household water treatment technologies such as solar disinfection, chlorine disinfection, and ceramic microfiltration, all of which have been found to reduce diarrheal disease from $30 \%$ to $70 \%$ in various field trials like this one. , $^{3,15,16}$

The BSF intervention had the greatest impact on children between 2 and 4 years of age. This may be explained by the fact that children in that age group are no longer being breastfed. They are also eating solid food and drinking many drinks in addition to milk that are prepared with water (such as juice). Furthermore, it is also possible that households boiling drinking water for very young children do not do so at all or consistently for children after age 2 , leaving this age group less protected against diarrheal disease. ${ }^{9}$ The size of the impact of 
TABLE 4

Results from random intercepts logistic regression model with and without the effect measure modification by season: odds ratios for diarrheal disease for biosand filter intervention during randomized controlled trial in Bonao, Dominican Republic, February-July 2006

\begin{tabular}{lcc}
\hline & OR* & $95 \%$ CI \\
\hline February-July 2006 & 0.53 & $0.36-0.79$ \\
Dry season 2006 $\dagger$ & 0.40 & $0.25-0.62$ \\
Wet season 2006 & 0.86 & $0.50-1.48$ \\
\hline * Odds ratio with control as referent group. & & \\
& † Dry season = months February, March, April, July; wet season = May and June.
\end{tabular}

the BSF on this age group deserves additional study both to determine whether it occurs in other locations and whether it is sustained over time or was an artifact of the population studied and sample size.

During the dry season, the diarrheal disease in BSF households was 0.40 times the diarrheal disease in the control households, a significant difference. During the wet season, diarrheal disease in BSF households was 0.86 times the diarrheal disease in the control households (a non-significant difference). The reduced protective effect of the BSF during the rainy season is likely caused by the decrease in diarrheal disease in the control group during the 2 months of observation of the wet season. The lower rates of diarrheal disease in the control group during the rainy season and the relatively short observation period $(2$ months) decreased the ability to resolve a statistically significant difference between the two groups during the rainy season.

In the dry season, the microbiological quality of drinking water may be worse than in the wet season. In this study, households relied more heavily on rain water as a source of drinking water during periods of high rainfall. In the dry season, households may turn to water sources that are more contaminated than rainwater such as surface water, wells, or intermittent piped supplies. Furthermore, households may also be forced to store drinking water for longer periods of time before consumption during the dry season. Household drinking water quality has been shown to deteriorate significantly during storage in the home, with such degradation being more substantial when the source water is relatively uncontaminated. ${ }^{17}$

Seasonal fluctuation in diarrheal disease. Seasonal transmission of diarrheal diseases and fluctuations in diarrheal disease rates with season are not unique to this study. Increases in diarrheal diseases are often seen during times of increased rainfall or during wet weather events. This phenomenon was documented in Gambia, where researchers found an increase

TABLE 5

Household drinking water quality in biosand filter and control households before and after biosand filter intervention (based on geometric mean $E$. coli concentrations during each period) during randomized controlled trial in Bonao, Dominican Republic, 2005-2006

\begin{tabular}{|c|c|c|c|}
\hline & Control & BSF & $P$ value" \\
\hline $\begin{array}{l}\text { Before BSF E. coli } / 100 \mathrm{~mL} \\
\quad(95 \% \mathrm{CI})\end{array}$ & $22(18-26)$ & $21(17-25)$ & 0.74 \\
\hline $\begin{array}{l}\text { After BSF E. coli } / 100 \mathrm{~mL} \\
\quad(95 \% \mathrm{CI})\end{array}$ & $19(16-22)$ & $11(9.3-13)$ & $<0.001$ \\
\hline $\begin{array}{l}P \text { value comparing } \\
\text { before/after }\end{array}$ & 0.21 & $<0.001$ & \\
\hline $\begin{array}{l}\text { Average difference in } \\
\text { E. coli/100 } \mathrm{mL} \dagger\end{array}$ & $9.8 \%$ & $48 \%$ & 0.01 \\
\hline
\end{tabular}

TABLE 6

Number (percentages) of samples by E. coli concentrations in household drinking water during biosand filter intervention period* in randomized controlled trial of the biosand filter in Bonao, Dominican Republic, February-July 2006

\begin{tabular}{|c|c|c|c|c|c|c|}
\hline E. coli & $<1 \dagger$ & $1-10$ & $11-100$ & $101-1,000$ & $>1,000$ & Total \\
\hline Control & $250(27.4)$ & $170(18.7)$ & 311 (34.1) & $123(13.5)$ & $57(6.3)$ & 911 \\
\hline BSF & $371(31.3)$ & $360(30.4)$ & $309(26.1)$ & $101(8.5)$ & $43(3.6)$ & 1184 \\
\hline
\end{tabular}

in diarrheal disease during summer rains. ${ }^{18}$ Other diarrheal disease transmission patterns, however, are associated with the dry season. For example, rotavirus transmission was more effective during the hot dry months in one study in Kenya. ${ }^{19}$ Diarrheal disease rates in Thailand were observed to decrease after summer rains began, much like the effect in this study, although the relationship was not highly correlated and probably influenced by other factors. ${ }^{20}$

In this study, diarrheal disease rates were reduced after the rainy season began. This happened twice in the control households in the 10-month study period: once before BSF intervention and once after BSF intervention. The observed periodicity in diarrheal disease rates, with higher levels in the dry season and declines in the wet season, suggests that the observed decrease in diarrheal disease in the BSF households is not likely to be an artifact of study fatigue. Such fatigue results in households reporting fewer cases of diarrheal disease as study time increases, without a rebound to reporting higher cases again.

Possible reasons why increased rainfall could result in decreased diarrheal disease rates include 1) switching to rainwater for drinking water instead of other, more contaminated sources and 2) increased quantities of rainwater available for other household needs, such as hand-washing, cleaning, or bathing. Numerous studies have shown significant reductions in diarrheal disease as a result of increased water supply., ${ }^{3,21}$ Hence, the abundance of rainwater possibly decreases exposure to diarrheal pathogens during the rainy season. The opposite effect, namely increased risk of diarrhea, may occur during periods of decreased rainfall or dry seasons. Households relying on rainwater for drinking and other critical uses during the wet season may have to use other, more contaminated water sources during the dry season or store rainwater for extended periods, increasing its risks of becoming contaminated with pathogens. Increased water storage time can result in degradation of rainwater microbial quality. ${ }^{17}$ In addition, during the dry season, there may be less water available overall for use in households relying on rainwater for a portion of their household water.

Effect of the BSF on household drinking water quality. Drinking water quality based on $E$. coli concentrations was better for BSF households compared with control households, with geometric mean concentrations lower by nearly $50 \%$. E. coli reductions in water of BSF households, however, were less than previously documented in both laboratory and field studies_ $~ 83 \%$ in this study compared with typically $90-99 \% .^{7,22}$ Unlike the water quality data of many other household water studies, the microbial quality of water was measured in all water designated for consumption in both BSF and control households. In BSF households, this included water directly from the BSF outlet, stored BSF-treated water, and untreated sources, if households indicated untreated 
water was being consumed. Likewise, drinking water from control households included both untreated water designated for consumption as well as treated water (e.g., stored boiled, stored chlorinated, and purchased bottled water). Therefore, the estimates of $E$. coli reductions by BSF treatment are likely to be underestimates of the actual reductions in filtrate water coming directly from the BSF treatment process. However, the measured $E$. coli concentrations of the various waters consumed in the households more accurately estimate the actual quality of the drinking water being consumed as a measure of exposure in both groups of households. Clear links and consistent relationships have not been established between household levels of E. coli in drinking water, and diarrheal disease risks and studies on household water treatment document decreases in diarrheal disease that are often difficult to link to improved microbial water quality. ${ }^{17}$

Limitations of this study. It is important to note that, because of the lack of a placebo BSF, the ability to determine whether the reduction of diarrheal disease was the result of under-reporting of diarrheal disease by BSF households is not possible. This placebo (Hawthorne) effect resulting from study participants under-reporting illness is a limitation of the study design. Nearly all of the $>20$ other epidemiologic field trials of household water treatment technologies in developing countries have also lacked the use of placebos, including those for solar disinfection, chlorine disinfection, coagulation-flocculation-disinfection product, and ceramic microfiltration. ${ }^{23,24}$ Additional research is recommended to determine whether the effect of the BSF on diarrheal disease rates was influenced by such a placebo effect. This may prove difficult because of the technical challenges of designing a placebo or sham concrete BSF for household use.

It was also not possible to measure filter acceptance, use, or compliance with recommendations for proper water management in BSF households. The reduced concentration of E. coli in drinking water in BSF households suggests that households were using improved water, and this was likely the result of BSF use. In addition, turbidity of treated water was lower than untreated water of both BSF and control households (data not shown). This finding is consistent with water filtration, which is well known to reduce water turbidity. However, there is no treatment-related agent to measure in the treated water, as there is for example in chlorine intervention studies, where one can measure the free chlorine concentration in the water. Additional studies of BSFs in the field found high levels of acceptance and continued use. ${ }^{22,25}$ Furthermore, the extent to which these results can be generalized beyond this particular location and setting is uncertain. For the BSF to be documented as robust and consistently effective as the other technologies, this type of field trial should be repeated in other locations and under other circumstances. Field studies in other regions of the world have been completed or are in progress to evaluate whether the BSF improves water quality and reduces diarrheal disease. Their findings will help to determine whether the results observed here are repeatable and generalizable.

Received March 11, 2008. Accepted for publication October 23, 2008.

Acknowledgments: The authors thank all of the study participants from the communities of Jayaco and Brisas del Yuna, Bonao, Dominican Republic. Without their time and patience, this study would not have been possible. We also thank the interviewers from the community of Jayaco, Bonao, DR, and the staff of Dr. Mirna Peña de
Guerra's laboratory for all of their technical assistance. Thanks also to Douglas Wait and the UNC Environmental Microbiology and Health group.

Financial support: Laboratory supplies for water quality testing were graciously donated by IDEXX Laboratories and Hach Company. We are grateful to the many Rotary Districts and Clubs of Michigan and Colorado, the Canadian Embassy of The Dominican Republic, the W. K. Kellogg Foundation, and the Fulbright Award for generous financial support of this study.

Authors' addresses: Christine E. Stauber, Georgia State University, Institute of Public Health, PO Box 3995, Atlanta, GA 30302-3995, Tel: 404-413-1128, Fax: 404-413-1140. Gloria M. Ortiz, University of North Carolina-Chapel Hill, School of Public Health, Department of Environmental Sciences and Engineering, CB 7431 Rosenau Hall 148, Chapel Hill, NC 27599-7431, Tel: 919-966-7316, Fax: 919966-7911. Dana Loomis, School of Public Health/271, University of Nevada, Reno, Reno, NV 89557-0036, Tel: 775-682-7103, Fax: 775-7841340. Mark D. Sobsey, University of North Carolina-Chapel Hill, School of Public Health, Department of Environmental Sciences and Engineering, CB 7431 Rosenau Hall, Chapel Hill, NC 27599-7431, Tel: 919-966-7303, Fax: 919-966-7911.

\section{REFERENCES}

1. Kosek M, Bern C, Guerrant RL, 2003. The global burden of diarrhoeal disease, as estimated from studies published between 1992 and 2000. Bull World Health Organ 81: 197-204.

2. Pruss-Ustun A, Corvalan C, 2006. How much disease burden can be prevented by environmental interventions? Epidemiology 18: $1-12$.

3. Fewtrell L, Kaufmann RB, Kay D, Enanoria W, Haller L, Colford $\mathrm{JM} \mathrm{Jr}, 2005$. Water, sanitation, and hygiene interventions to reduce diarrhoea in less developed countries: a systematic review and meta-analysis. Lancet Infect Dis 5: 42-52.

4. Samaritan's Purse Canada Website. Available at: http://www .samaritanpurse.ca/ourwork/water/biosandfilter_technical. aspx. Accessed November 23, 2008.

5. Elliott MA, Stauber CE, Koksal F, DiGiano FA, Sobsey MD, 2008. Reductions of E. coli, echovirus type 12 and bacteriophages in an intermittently operated household-scale slow sand filter. Water Res 42: 2662-2670.

6. Palmateer G, Manz D, Jurkovic A, 1999. Toxicant and parasite challenge of Manz intermittent slow sand filter. Environ Toxicol 14: $217-225$.

7. Stauber CE, Elliott MA, Koksal F, Ortiz GM, DiGiano FA, Sobsey MD, 2006. Characterisation of the biosand filter for E. coli reductions from household drinking water under controlled laboratory and field use conditions. Water Sci Technol 54: $1-7$.

8. Joint Monitoring Program for Water Supply and Sanitation, 2006. Improved coverage estimates for the Dominian Republic. Available at: http://www.wssinfo.org/pdf/country/DOM_wat .pdf. Accessed November 23, 2008.

9. McLennan JD, 2000. Prevention of diarrhoea in a poor District of Santo Domingo, Dominican Republic: practices, knowledge, and barriers. J Health Popul Nutr 18: 15-22.

10. Demographic and Health Survey, 2003. Encuesta demografica y de salud: Republica Dominicana. Available at: http://www. measuredhs.com/pubs/pdf/FR205/FR205.pdf. Accessed November 23, 2008.

11. Vyas S, Kumaranayake L, 2006. Constructing socio-economic status indices: how to use principal components analysis. Health Policy Plan 21: 459-468.

12. Kleinbaum D, Kupper L, Morgenstern H, 1982. Epidemiologic Research: Principles and Quantitative Methods. Belmont, CA: Lifetime Learning Publications.

13. Greenland S, 1989. Modeling and variable selection in epidemiologic analysis. Am J Public Health 79: 340-349.

14. Rabe-Hesketh S, Skrondal A, 2005. Multi-Leveling and Longitudinal Modeling Using Stata. College Station, TX: Stata Press.

15. Arnold BF, Colford JM Jr, 2007. Treating water with chlorine at point-of-use to improve water quality and reduce child 
diarrhea in developing countries: a systematic review and meta-analysis. Am J Trop Med Hyg 76: 354-364.

16. Clasen T, Garcia Parra G, Boisson S, Collin S, 2005. Householdbased ceramic water filters for the prevention of diarrhea: a randomized, controlled trial of a pilot program in Colombia. Am J Trop Med Hyg 73: 790-795.

17. Wright J, Gundry S, Conroy R, 2004. Household drinking water in developing countries: a systematic review of microbiological contamination between source and point-of-use. Trop Med Int Health 9: 106-117.

18. Rowland MG, 1986. The Gambia and Bangladesh: the seasons and diarrhoea. Dialogue Diarrhoea 26: 3.

19. Mutanda LN, Kinoti SN, Gemert W, Lichenga EO, 1984. Age distribution and seasonal pattern of rotavirus infection in children in Kenya. J Diarrhoeal Dis Res 2: 147-150.

20. Pinfold JV, Horan NJ, Mara DD, 1991. Seasonal effects on the reported incidence of acute diarrhoeal disease in northeast Thailand. Int J Epidemiol 20: 777-786.
21. Esrey SA, Feachem RG, Hughes JM, 1985. Interventions for the control of diarrhoeal diseases among young children: improving water supplies and excreta disposal facilities. Bull World Health Organ 63: 757-772.

22. Duke WF, Nordin RN, Baker D, Mazumder A, 2006. The use and performance of BioSand filters in the Artibonite Valley of Haiti: a field study of 107 households. Rural Remote Health 6: 570.

23. Fewtrell L, Colford JM Jr, 2005. Water, sanitation and hygiene in developing countries: interventions and diarrhoea-a review. Water Sci Technol 52: 133-142.

24. Clasen T, Roberts I, Rabie T, Schmidt W, Cairncross S, 2006. Interventions to improve water quality for preventing diarrhoea. Cochrane Database Syst Rev 3: CD004794.

25. Kaiser N,Liang K, Maertens M,Snider R,2002. Biosand Household Water Filter Evaluation 2001: A Comprehensive Evaluation of the Samaritan's Purse Biosand Filter (BSF) Projects in Kenya, Mozambique, Cambodia, Vietnam, Honduras and Nicaragua. Samaritan's Purse Canada. 